\section{Olive Floral Bud Growth and Starch Content During Winter Rest and Spring Budbreak}

\author{
Raul De la Rosa and Luis Rallo \\ Departamento de Agronomía, Escuela Técnica Superior de Ingenieros \\ Agrónomos y Montes, Universidad de Córdoba, Apdo 3048, 14080 Córdoba, \\ Spain
}

\author{
Hava F. Rapoport ${ }^{1}$ \\ Instituto de Agricultura Sostenible, Consejo Superior de Investigaciones \\ Científicas, Apdo 4084, 14080 Córdoba, Spain
}

Additional index words. endodormancy, floral differentiation, Olea europaea

\begin{abstract}
In the olive (Olea europaea L.), inflorescence and flower differentiation occur in the early spring following a period of winter chilling and dormancy of the potentially reproductive buds. We examined the size, structure, and starch content of these buds during winter rest in the field and during forcing under standard growth-chamber conditions. Basic bud structure and dimensions remained unchanged during the rest period, but starch content increased in the bud's central axis. When cuttings were forced in the growth chamber, the buds followed a morphogenetic pattern similar to that observed in the field, but the sequence of developmental events could be timed more precisely. The first changes observed were the onset of axis growth and the differentiation of axillary primordia within 3 days of transfer to the growth chamber. This was followed by the initiation of new nodes, and, at 15 to 18 days, by the first signs of floral differentiation in the terminal and axillary bud apical meristems. Bud growth and differentiation were accompanied by a decrease in starch content.
\end{abstract}

Olive flowering occurs in axillary buds of the previous year's growth. Traditionally, winter chilling accumulation was believed to be required for floral induction (Hackett and Hartmann, 1963, 1964, 1967), although more recent experimental data suggest that floral induction occurs prior to winter rest (FernándezEscobar et al., 1992; Navarro et al., 1990; Pinney and Polito, 1990; Stutte and Martin, 1986). This latter interpretation is further supported by Rallo and Martin (1991), who determined that winter chilling in olive is required to release previously initiated buds from dormancy, rather than to induce floral induction.

Studies of floral differentiation in olive buds have detected no changes during winter (Almeida, 1940; Hackett and Hartmann, 1963) although Pinney and Polito (1990) found changes in floral bud size and RNA content. The morphological development of reproductive buds toward the end of winter, when budbreak occurs, has been characterized (Almeida, 1940; Hackett and Hartmann, 1963; King, 1938; Troncoso, 1968), but there is no

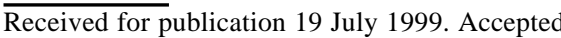
for publication $11 \mathrm{Jan}$. 2000. This study was supported by Comisión Interministerial de Ciencia y Tecnología project AGF 95-0734-CP. The cost of publishing this paper was defrayed in part by the payment of page charges. Under postal regulations, this paper therefore must be hereby marked advertisement solely to indicate this fact.

${ }^{1}$ To whom requests for reprints should be addressed. E-mail address: ag2rapop@uco.es events or the timing of the structural changes involved. The high heterogeneity in the time of budbreak in the field, even among individual buds on the same branch (Troncoso, 1968), suggests the value of using standard conditions to examine the changes that occur during the release of reproductive buds from dormancy (Rallo and Martin, 1991).

Woody shoot explants have been utilized with great success to provide standardized conditions for studying dormancy release in buds of deciduous fruit trees (Saure, 1985). Rallo and Martin (1991) adapted the use of woody shoot explants to examine the role of chilling in release of dormancy in initiated olive floral buds. They reported healthy viable material and budbreak activity up to 10-12 weeks after the leafy cuttings were removed from the tree and transferred to controlled experimental conditions.

Besides structural modifications, changes in starch accumulation in the floral bud during winter rest and at budbreak have been related to chilling accumulation and dormancy release in peach [Prunus persica (L.) Batsch.] (Feng et al., 1974), sour cherry (P. cerasus L.) (Felker et al., 1983), and other fruit tree species (Lavee, 1973).

We attempted to characterize the structural aspects and the changes in starch accumulation of potentially reproductive floral buds during endodormancy and in the early stages of budbreak in olive. We removed buds from trees in the field at different times during the clear indication of the precise sequence of endodormancy period, and also forced budbreak in woody shoot explants in a controlled environment in order to achieve standardized conditions for this process.

\section{Materials and Methods}

Plant material. Axillary buds were obtained from five 'Manzanillo' olive trees at the Alameda del Obispo experimental farm in Córdoba, Spain. The trees yielded poorly $(<5$ $\mathrm{kg} /$ tree) the previous season, so, since the olive tree is highly alternate bearing, the majority of the buds were expected to be reproductive. Flowering status was confirmed by observations of bud development in growth chamber studies and by field observations of bud growth later in the season.

Sampling procedure. Two different sampling series were carried out to characterize floral bud behavior during winter rest and budbreak.

Rest period. Mid-shoot buds were collected from representative previous-year shoots of the trees described above, on three different dates (10 Nov. and 12 Dec. 1994 and 20 Jan. 1995). These dates represent different periods (initial, middle, and final rest) in the winter rest (endodormancy) period as determined in previous studies (Fabbri and Alerci, 1999; Hackett and Hartmann, 1964; 1967; Troncoso, 1968). The last date was about the time of rest release (Rallo and Martin, 1991), and prior to budbreak.

Budbreak at rest release. One-year shoots, similar to those used for the rest-period bud sampling, were collected from the same trees on the final endodormancy date (20 Jan. 1995). The shoot explants were placed in the growth chamber for floral budbreak under uniform conditions as described by Rallo and Martin (1991). Shoots with $\approx 12$ nodes were cut in the field and immersed in water for transport to the laboratory. There, six-node leaf-bearing explants were prepared, placed in vials containing 8-hydroxyquinoline citrate (8$\mathrm{HQC}$ ) at $200 \mathrm{mg} \cdot \mathrm{L}^{-1}$, and put in the growth chamber at $10^{\circ} \mathrm{C}$ night $/ 21^{\circ} \mathrm{C}$ day with photosynthetic photon flux density $(P P F)$ of 275 $\mu \mathrm{mol} \cdot \mathrm{m}^{-2} \cdot \mathrm{s}^{-1}$. The floral buds were sampled every $3 \mathrm{~d}$ (days $3,6,9,12,15$, and 18) for anatomical studies.

Bud preparation. All floral buds were fixed in FAE (formalin : acetic acid : $60 \%$ ethanol $=2: 1: 17$ l.c.), embedded in paraffin, sectioned at $12 \mu \mathrm{m}$, and stained in safranincrystal violet-light green yellowish (SAF-CV-LGY) (Gerlach, 1969) for floral bud general structure, and in iodine : potassium iodide (IKI) (Jensen, 1962) for starch identification. The floral buds were sectioned longitudinally, with the cut surface parallel to the axis between the petiole of the subtending leaf and the shoot, using the petiole as an aid for orientation (Fig. 1). Since olive buds are decussate, the bracts of the odd-numbered nodes were all visible in the central longitudinal sections (Fig. 2). A complete set of serial sections was made from each bud, so the even-numbered nodes were counted and observed in other noncentral sections. 


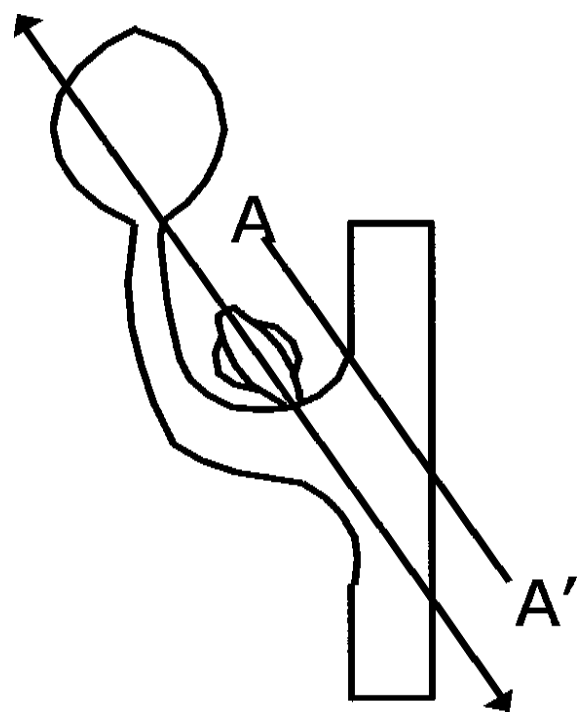

Fig. 1. Cutting orientation of olive buds (arrow) for sectioning. The buds were sectioned longitudinally, with the cut surface parallel to the axis (A-A') lying between the petiole of the subtending leaf and the shoot.

Bud measurement. The sections were observed, and the nodes counted. Measurements of bud dimensions of the central longitudinal sections were made using an optical microscope with image analysis (VIDS V; Ai Cambridge, Pampisford, U.K.). Bud axis height and width (Fig. 2B) were determined for at least seven samples per date and the data obtained were processed by regression analysis. Additionally, the apical dome width was measured in the growth chamber samples.

\section{Results and Discussion}

Our observations characterized changes in size, structure, and starch content of potentially reproductive olive buds during winter rest in the field and during budbreak forced under standardized growth chamber conditions. Under these conditions, floral budbreak is indicative of the time of rest release. Therefore, the changes at this time should anticipate later bud differentiation under field conditions.

Rest period. On the first sampling date (initial rest), the buds had four to five nodes, each with two bracts inserted at the same height in opposite positions. Bud primordia occurred in the bract axils of the most basal (first) node, and meristematic zones in the bract axils of the second (not shown) and third node (Fig. 2A). No differences were observed in this basic structure, including the number of nodes, between buds sampled at the early, mid, and final rest dates, nor were there significant differences among dates in any of the bud dimensions measured (Fig. 3). The structure of the potentially floral bud before winter rest (Fig. 2) is consistent with descriptions by Almeida (1940) and Hackett and Hartmann (1963), who also observed axillary bud primordia in the basal nodes. Pinney and Polito (1990) and Fabbri and Alerci (1999) described
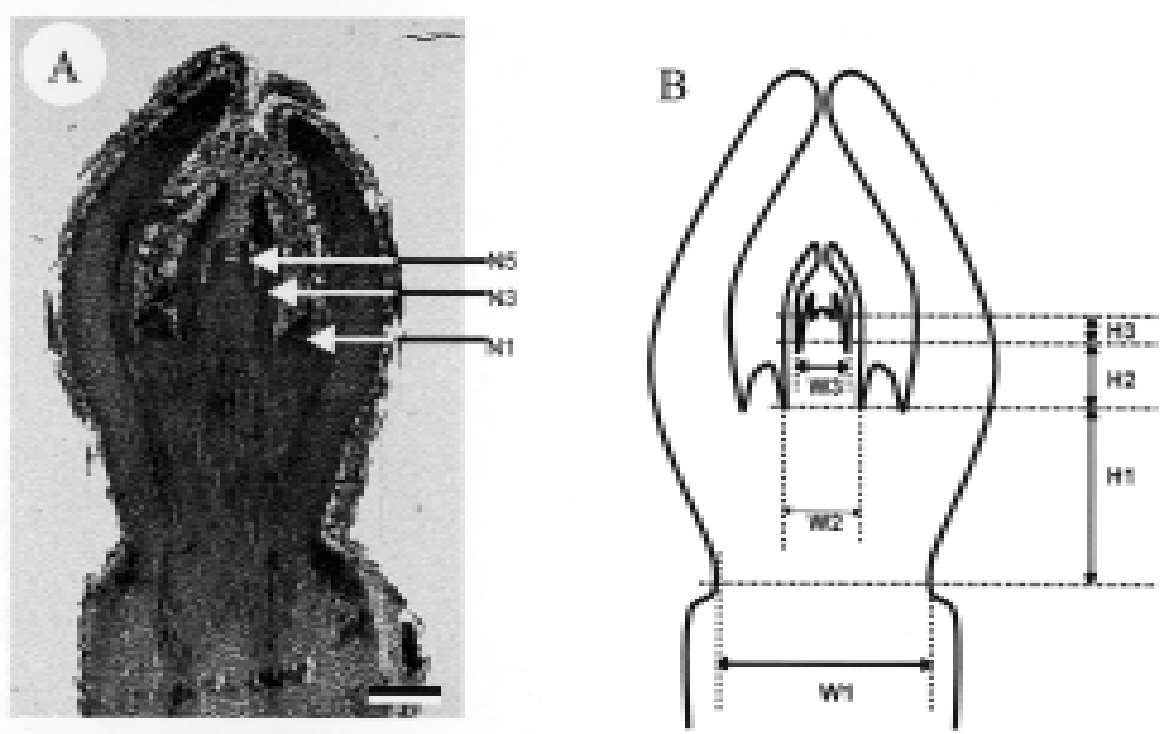

Fig. 2. Olive bud structure. (A) Median longitudinal section of floral bud collected on 10 Nov. 1994, stained with SAF-CV-LGY. Due to its decussate structure, only three (N1, N3, and N5) of the five nodes of the bud are visible. Each node is formed by two bracts; at this stage there were axillary primordia in the most basal node (N1). Bar $=250 \mu \mathrm{m}$. (B) Diagram of section 2A with measurements indicated. W1 $=$ width of bud base; W2 = width of bud axis at the level of the axils of the first pairs of bracts; W3 = width of bud axis at the level of the axils of the third pairs of bracts; $\mathrm{H} 1=$ height of the base of the first node; $\mathrm{H} 2=$ height of the base of the third node; $\mathrm{H} 3$ = height of the base of the fifth node. The width of the apical dome was also measured.
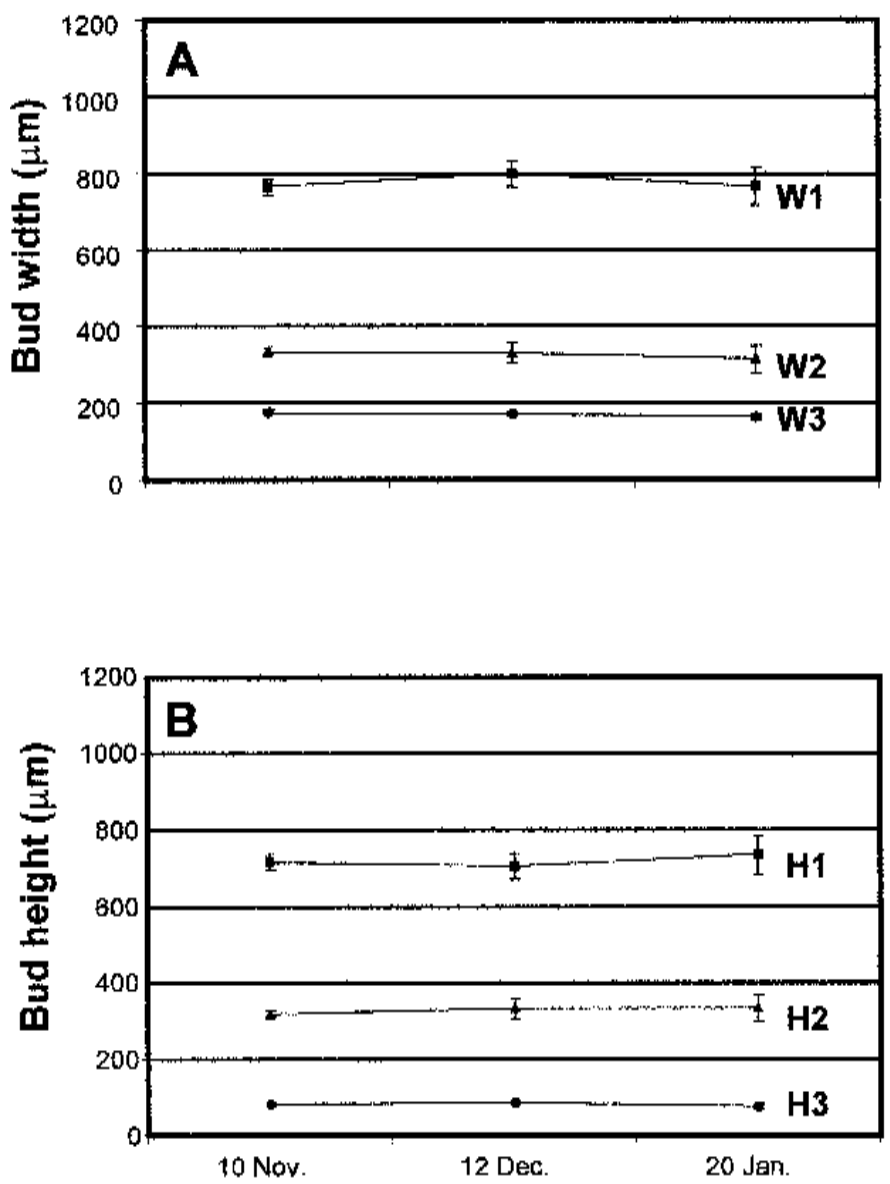

\section{Sampling date}

Fig. 3. (A) width and (B) height of olive floral buds on three sampling dates representing early, middle and final rest. The dimensions measured (W1, W2, W3, H1, H2, and H3) are diagrammed in Fig. 2B. Bars represent SE. 

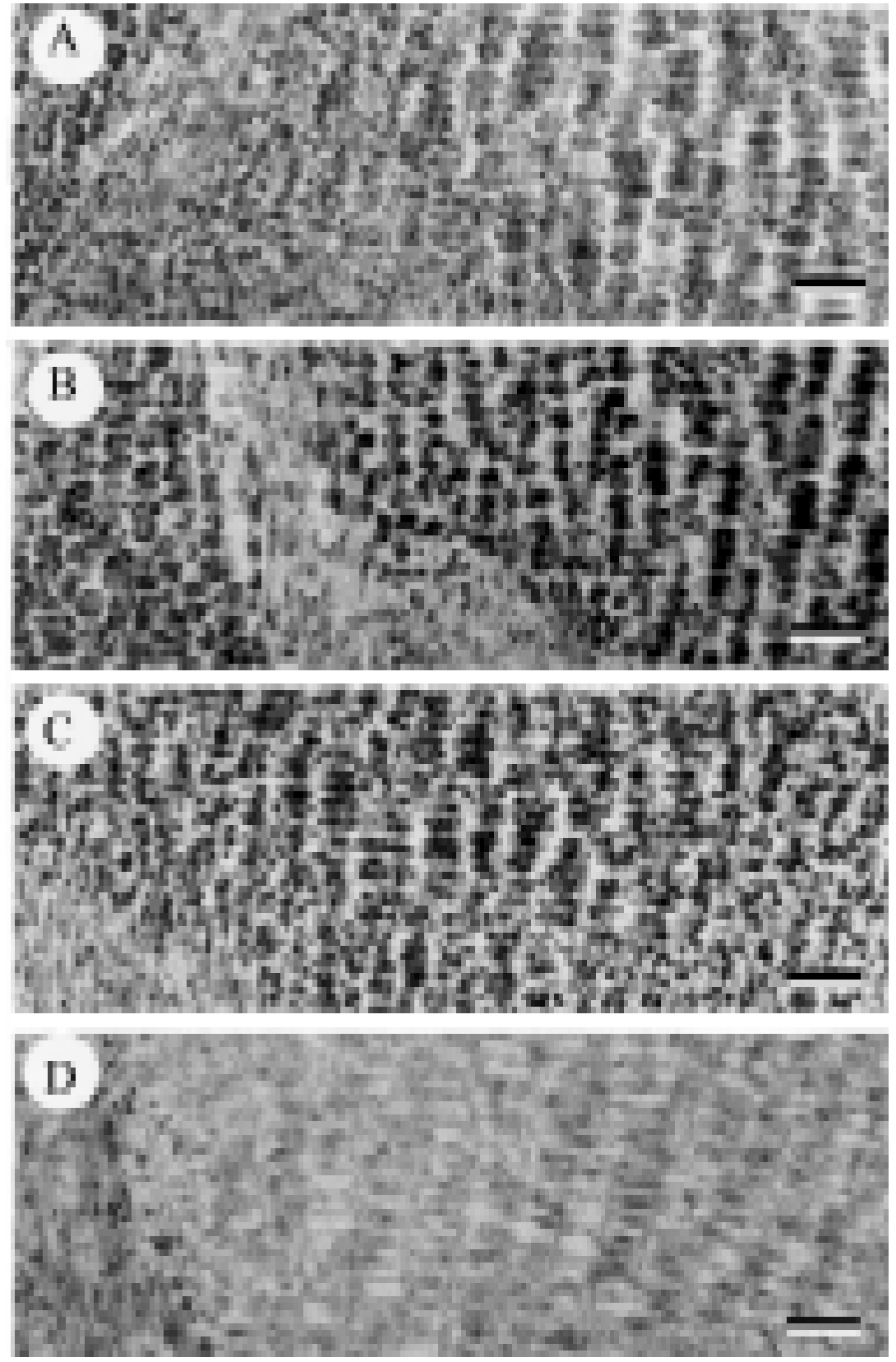

Fig. 4. Central sections of olive floral buds after staining with IKI. The zone pictured corresponds to H1 in Fig. 2B. Starch grains appear as dark spots. Bar $=50 \mu \mathrm{m}$. (A) Early rest (10 Nov. 1994); (B) final rest (20 Jan. 1995); (C) day 3 in growth chamber; and (D) day 9 in growth chamber. A and $\mathbf{B}$ were sampled during rest, $\mathbf{C}$ and $\mathbf{D}$ at different times during bud break in the growth chamber.

similar structure but did not observe axillary bud primordia until later dates. The lack of observable morphological change during winter rest agrees with the studies by Almeida (1940), Hackett and Hartmann (1963), and Fabbri and Alerci (1999). Pinney and Polito (1990), however, observed elongation of the floral bud axis between mid-November and budbreak in late February, although there was no increase in node number.

Staining for starch with IKI revealed a low level of starch grains in the bud at early rest (Fig. 4A) and an increase in both grain number and size at final rest (Fig. 4B). The increase in starch content associated with accumulated chilling during the rest period has been ob- axillary meristems were visible at the fifth node (Fig. 5C). After $12 \mathrm{~d}$, axillary buds at the first node started to branch (Fig. 5D), similar to the development observed by Hackett and Hartmann (1963) for 18 Mar. and by Almeida (1940) on 21 Feb.

On day 12 , the axillary buds or bud primordia of the first six nodes were clearly visible. The first signs of floral differentiation appeared on day 15 when, in the first and third node axillary buds the apices presented a central identation (Fig. 6A). This structure appeared in the terminal meristem $3 \mathrm{~d}$ later (Fig. 6B). Almeida (1940) described this phenomenon as occurring first in the terminal meristem, on 2 Mar., followed soon after in the lateral buds. Troncoso (1968) considered these apical changes the first definitive evidence of olive floral differentiation. In field studies, such changes have been detected at different times depending on cultivar and climatic conditions (Almeida, 1940; Fabbri and Alerci, 1998; Hackett and Hartmann, 1963; Troncoso, 1968).

The number of starch grains increased slightly until day 3 after placement in the growth chamber (Fig. 4B-C). The starch then disappeared progressively, with only a few grains remaining near the vascular tissue on day 9 (Fig. 4D). These results suggest that starch is used as an energy source in the early stages of budbreak and inflorescence growth and development, and agree with Lavee's (1973) observation that the breaking of rest coincided with a sharp decrease in starch content.

Node number (Fig. 7) increased from five on day 6 to seven on day 12. Fabbri and Alerci (1999) observed the addition of two to three nodes during floral budbreak in the cultivar Nocellara Etnea and Hackett and Hartman (1963) reported seven nodes in a 'Manzanillo' inflorescence bud on 2 Apr. The width of the apical dome appeared to shrink and swell (Fig. 7), possibly in coordination with the formation of new nodes, as is typical for leaf initiation activity in shoot apical meristems (Steeves and Sussex, 1989). The range in width of the apical dome (Fig. 7) was similar to those presented by Fabbri and Alerci (1999) for flower bud apex widths.

Width and height of the different parts of the bud axis increased during the $18 \mathrm{~d}$ in the growth chamber (Fig. 8). The greatest changes were in elongation in the oldest inflorescence axis regions ( $\mathrm{H} 1$ and $\mathrm{H} 2)$. Growth in width (Fig. 8A) and length (Fig. 8B) for all zones started at the earliest dates, i.e., as soon as the explants were placed in conditions favorable for budbreak. Both linear and quadratic regressions for those data (Fig. 8) were performed and both were found significant $(P \leq$ 0.0001 for all variables). For the linear regressions, $R^{2}$ ranged from 0.47 to 0.66 . When a quadratic regression model was used, $R^{2}$ was higher than in the linear regression for the dimensions $\mathrm{H} 1, \mathrm{H} 3, \mathrm{~W} 1$, and $\mathrm{W} 2$. Table 1 presents the best regression (linear or quadratic) values for each dimension.

Both linear and quadratic regressions for bud dimensions were significant (Table 1). 

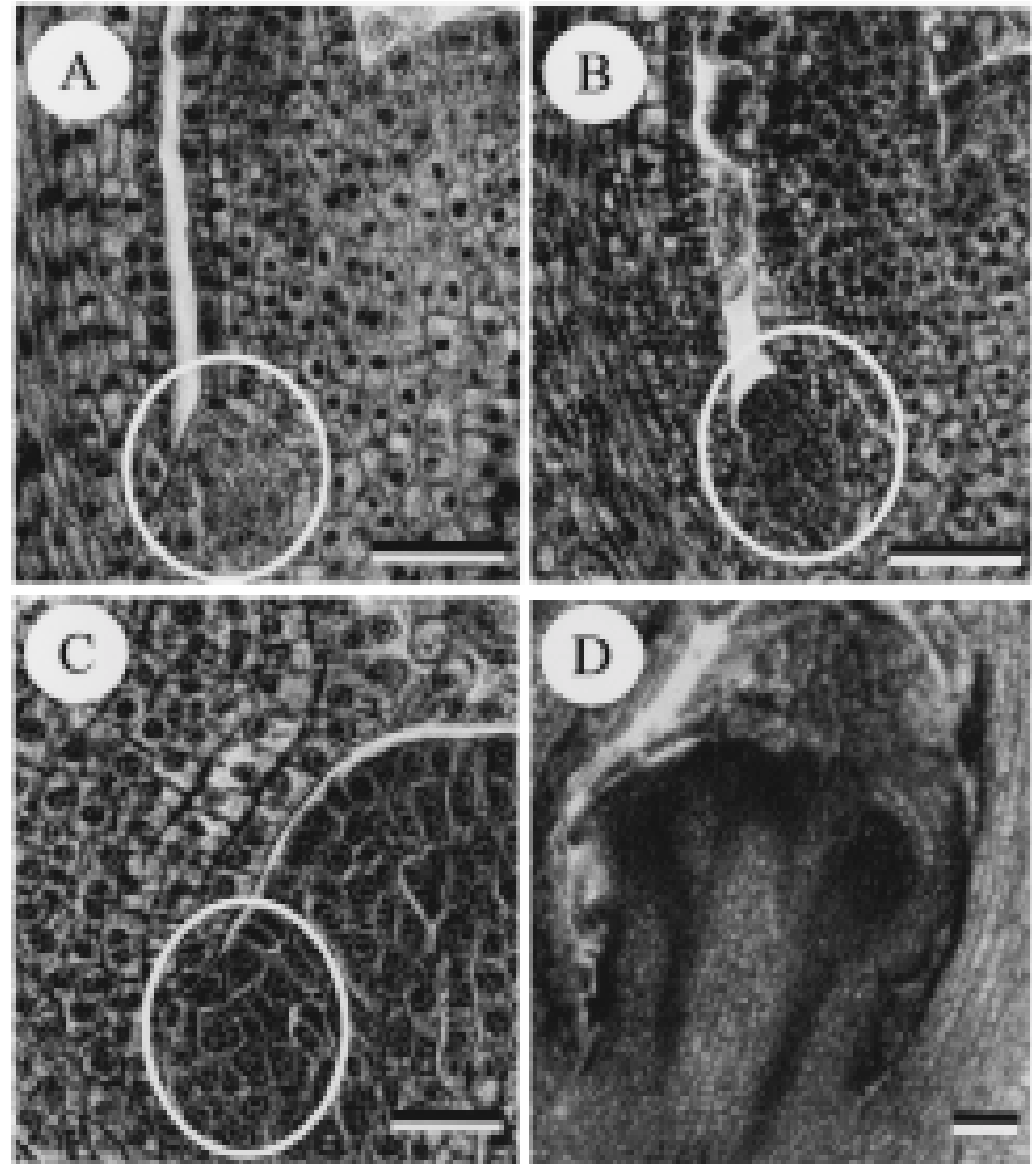

Fig. 5. Morphogenetic activity in the axils of the bracts of olive buds as indicated by staining with SAF-CV-LGY. Bar $=50 \mu \mathrm{m}$. (A) Axil of third node on final rest date (axillary meristematic zone within circle); (B) axil of third node after $3 \mathrm{~d}$ in the growth chamber (axillary bud primordium within circle); (C) axil of fifth node after $9 \mathrm{~d}$ in the growth chamber (axillary meristematic zone within circle); (D) axil of first node after $12 \mathrm{~d}$ in growth chamber (branched axillary bud).
Therefore, the rate of growth of the bud axis may have declined after $12 \mathrm{~d}$ (Fig. 8), when initiation of new nodes on the main axis ceased (Fig. 7). Intensive developmental activity occurred in both axillary (Figs. 5D, 6A) and apical (Fig. 6B) regions at this time, so a decline in axis growth rate could represent a redirection of resource utilization. A reduction in growth of the bud axis because of a loss of vitality or substrate availability in the explants, seems unlikely since Rallo and Martin (1991) demonstrated active budbreak in similar olive woody leaf-bearing explants after as long as 10-12 weeks.

Both the sequence and morphological pattern of budbreak observed for buds on cuttings in the growth chamber were generally similar to those described for olive buds in vivo in the field (Almeida, 1940; Fabbri and Alerci, 1999; Hackett and Hartmann, 1963; Troncoso, 1968). Furthermore, the explant system allowed the synchronization of budbreak and early inflorescence differentiation under controlled, standardized conditions; this permitted the accurate observation of morphological changes, as well as quantitative measurements, that could not be achieved under the highly variable conditions in the field (Almeida, 1940; Fabbri and Alerci, 1999; Fenández-Escobar et al., 1992; Troncoso, 1986). Similar standardization was not required for the winter rest period since the time interval was much greater and developmental activity highly reduced.

In summary, olive bud development during winter rest and budbreak was characterized as follows: at the onset of winter rest, the buds contained five nodes, with bud primordia in the axils of the most basal node (Figs. 2 and 3 ). That structure was maintained throughout the rest period, and bud starch content increased considerably (Fig. 4 A-C). Active growth and development started as soon as the buds, having completed winter rest, were placed in favorable conditions for budbreak. The earliest changes, apparent at $3 \mathrm{~d}$, were in growth of the bud axis (Fig. 8) and formation
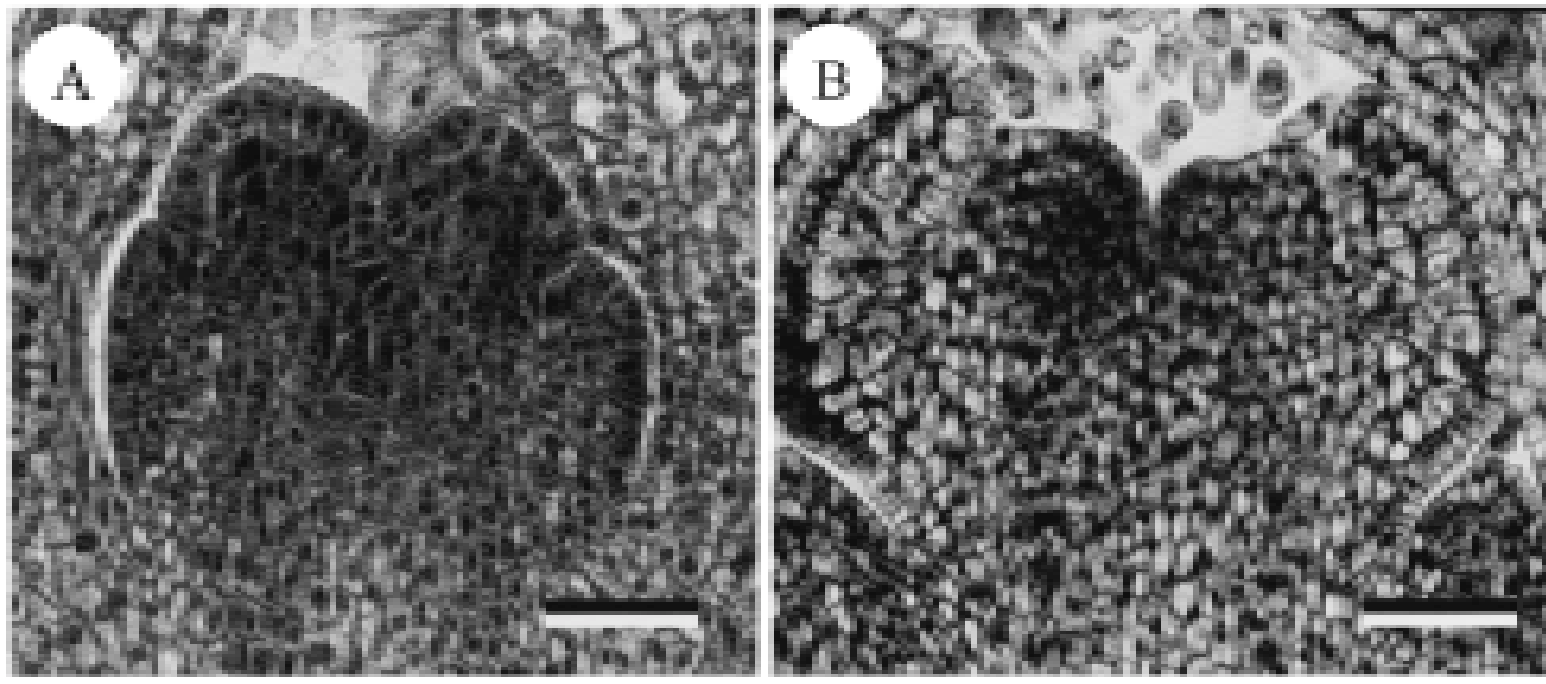

Fig. 6. Floral differentiation in olive buds as indicated by staining by SAF-CV-LGY. Bar $=50 \mu \mathrm{m}$. (A) Apical meristem of lateral bud of the first node after $15 \mathrm{~d}$ in the growth chamber; $(\mathbf{B})$ terminal meristem at $18 \mathrm{~d}$. 


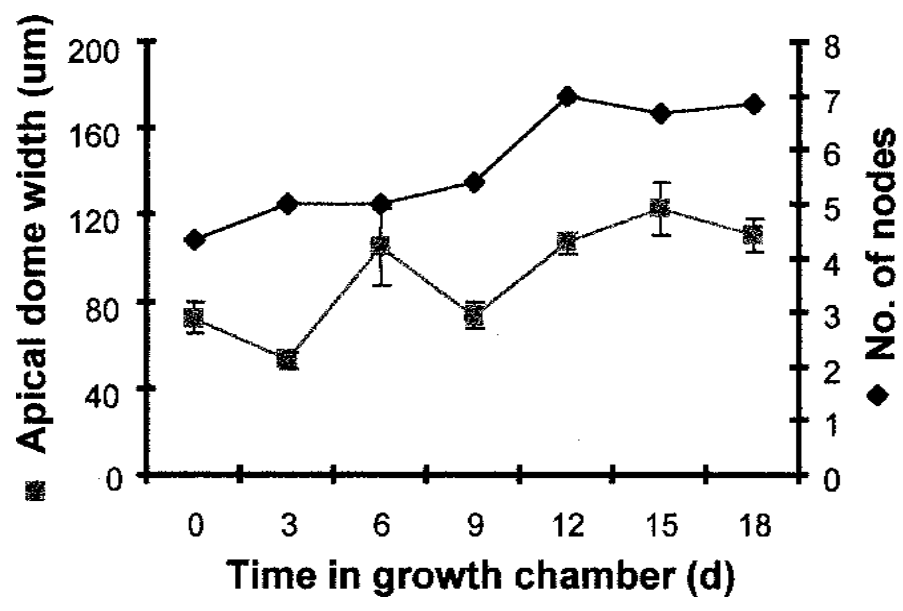

Fig. 7. Number of nodes and apical dome width during initial growth of olive buds in growth chamber conditions favorable for budbreak. Bars represent SE.
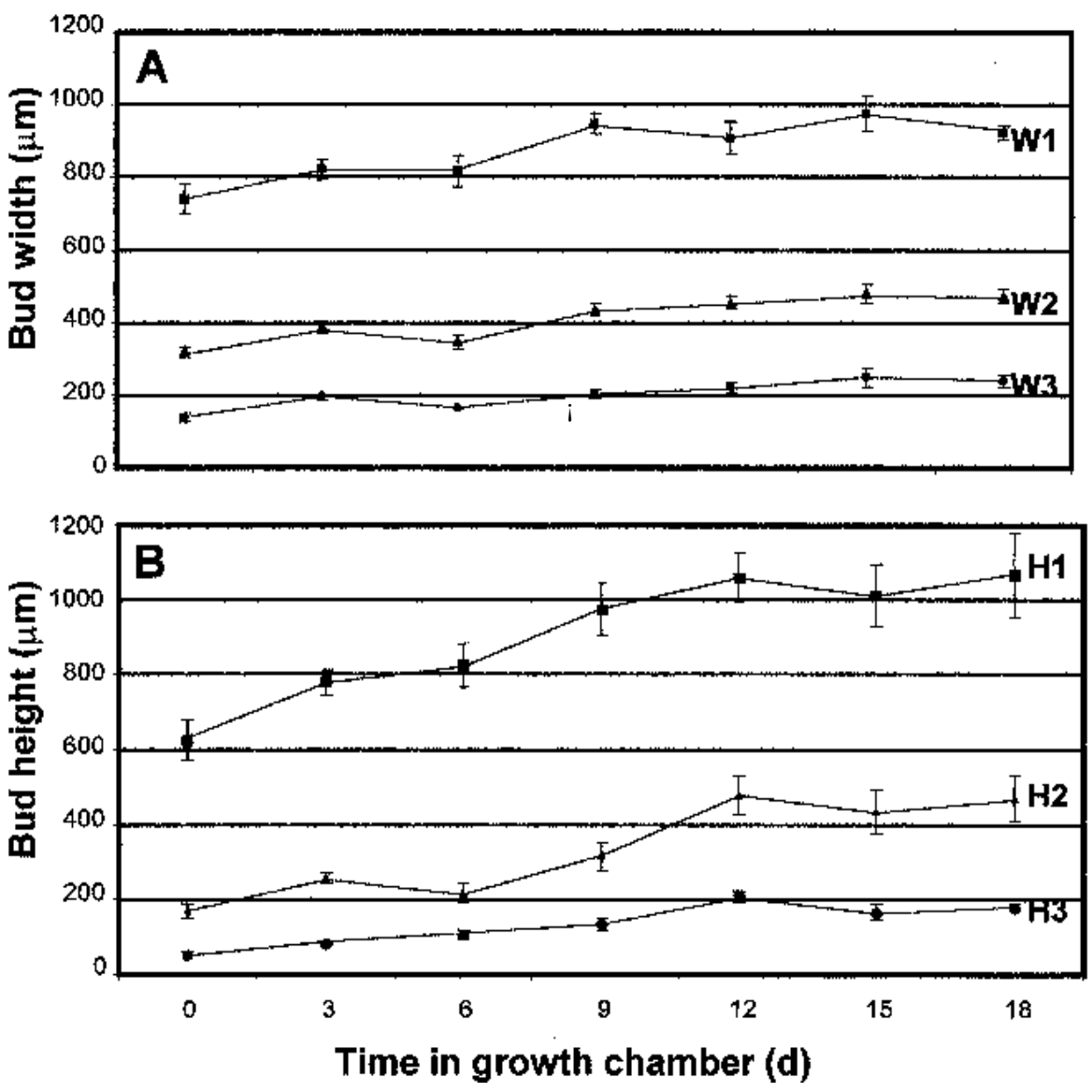

Fig. 8. (A) width and (B) height of olive floral buds during growth chamber forcing conditions. The dimensions measured (W1, W2, W3, H1, H2, and H3) are diagrammed in Fig. 2B. Bars represent standard errors. Both linear and quadratic regressions were highly significant $(P<0.001)$ in all cases, except for $\mathrm{H} 1$.

Table 1. Best regressions between bud dimensions $(\mu \mathrm{m}$, see Fig. 8$)$ and time $(\mathrm{t})$ in days after 20 Jan. Both linear and quadratic regressions were significant, and the best value for each dimension is presented.

\begin{tabular}{lccccc}
\hline \hline & & \multicolumn{3}{c}{ Significance of } \\
\cline { 3 - 6 } Dimension & Adjusted $R^{2 z}$ & Equation & Constant & $\mathrm{t}$ coef. & $\mathrm{t}^{2}$ coef. \\
\hline H1 & 0.49 & $626+50.3 \mathrm{t}-1.44 \mathrm{t}^{2}$ & 0.0001 & 0.0001 & 0.07 \\
$\mathrm{H} 2$ & 0.55 & $175+18 \mathrm{t}$ & 0.0001 & 0.0001 & -- \\
$\mathrm{H} 3$ & 0.69 & $43.3+15.4 \mathrm{t}-0.42 \mathrm{t}^{2}$ & 0.0003 & 0.0001 & 0.02 \\
W1 & 0.39 & $739+26.1 \mathrm{t}-0.85 \mathrm{t}^{2}$ & 0.0001 & 0.0003 & 0.06 \\
W2 & 0.63 & $301+18 \mathrm{t}-0.45 \mathrm{t}^{2}$ & 0.0001 & 0.0002 & 0.06 \\
W3 & 0.50 & $152+5.4 \mathrm{t}$ & 0.0001 & 0.0001 & -- \\
\hline
\end{tabular}

${ }^{\mathrm{z}}$ All values significant at $P \leq 0.0001$. of bud primordia in the axillary meristematic zones (Fig. 6B). From 6-12 d axis growth continued (Fig. 8), two additional nodes were initiated (Fig. 7) and axillary zone morphogenesis progressed (Fig. 5 C-D). By 15-18 d, the end of the period studied, developmental activity was dominated by increased growth and branching of the lateral buds and the onset of floral differentiation, first visible in basal axillary buds (Fig. 6A) and then at $18 \mathrm{~d}$ in the principal apex (Fig. 6B). During budbreak, the starch content of the central zone of the bud initially increased and then decreased gradually as bud development progressed (Fig. 4).

\section{Literature Cited}

Almeida, F.J. de. 1940. Safra e contra-safra na oliveira. Bul. Port. Min. Agr. No. 7. Lisbon.

Fabbri, A. and L. Alerci. 1999. Reproductive and vegetative bud differentiation in Olea europaea L. J. Hort. Sci. Biotech. 74:522-527.

Felker, F.C., H.A. Robtaille, and F.D. Hess. 1983. Morphological and ultrastructural development and starch accumulation during chilling of sour cherry flower buds. Amer. J. Bot. 70:376-386.

Feng, Y., W.F. Campbell, and D.R. Walker. 1974. Ultrastructural changes in peach flower buds during rest. J. Amer. Soc. Hort. Sci. 99:427432.

Fernandez-Escobar, R., M. Benlloch, C. Navarro, and G.C. Martin. 1992. The time of floral induction in the olive. J. Amer. Soc. Hort. Sci. 117:304307.

Gerlach, D. 1969. A rapid safranin-crystal violetlight green staining sequence for paraffin sections of plant materials. Stain Technol. 44:210211

Hackett, W.P. and H.T. Hartmann. 1963. Morphological development of buds of olive as related to low temperature requirement for inflorescence formation. Bot. Gaz. 124:385-387.

Hackett, W.P. and H.T. Hartmann. 1964. Inflorescence formation in the olive as influenced by low temperature, photoperiod and leaf area. Bot. Gaz. 125:65-72.

Hackett, W.P. and H.T. Hartmann. 1967. The influence of temperature on floral initiation in the olive. Physiol. Plant. 20:430-436.

Jensen, W.A. 1962. Botanical histochemistry. Freeman, San Francisco.

King, J.R. 1938. Morphological development of the fruit of the olive. Hilgardia 11:437-455.

Lavee, S. 1973. Dormancy and budbreak in warm climates: Considerations of growth regulator involvement. Acta Hort. 34:225-233.

Navarro, C., R. Fernandez-Escobar, and M. Benlloch. 1990. Flower bud induction in 'Manzanillo' olive. Acta Hort. 286:195-198.

Pinney, K. and V.S. Polito. 1990. Flower initiation in 'Manzanillo' olive. Acta Hort. 286:203-205.

Rallo, L. and G.C. Martin. 1991. The role of chilling in releasing olive floral buds from dormancy. J. Amer. Soc. Hort. Sci. 116:1058-1062.

Saure, M.C. 1985. Dormancy release in deciduous fruit trees. Hort. Rev. 7:239-300.

Steeves, T.A. and I. Sussex. 1989. Patterns in plant development. Cambridge Univ. Press.

Stutte, G.W. and G.C. Martin. 1986. Effect of killing the seed on return bloom of olive. Scientia Hort. 29:107-113.

Troncoso, A. 1968. Algunas observaciones sobre la evolución de las yemas del olivo (Olea europaea L.). Anales de Edafologia y Agrobiologia 27:259-276. 